\title{
COVID-19, VIROLOGY AND GEROSCIENCE: A PERSPECTIVE
}

\author{
C. VELLAS ${ }^{1,2}$, P. DELOBEL ${ }^{1,3,4}$, P. DE SOUTO BARRETO ${ }^{5,6}$, J. IZOPET ${ }^{1,2,4}$
}

\begin{abstract}
1. INSERM UMR1043 - CNRS UMR5282 Centre de Physiopathologie Toulouse-Purpan (CPTP), Toulouse, France; 2. Virology Laboratory, Toulouse University Hospital (CHU Toulouse), Toulouse, France; 3. Department of Infectious and Tropical Diseases, Toulouse University Hospital (CHU Toulouse), Toulouse, France; 4. University of Toulouse III Paul

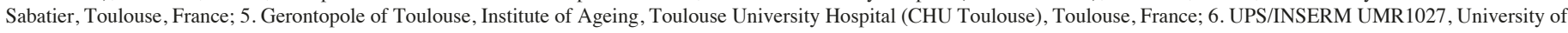

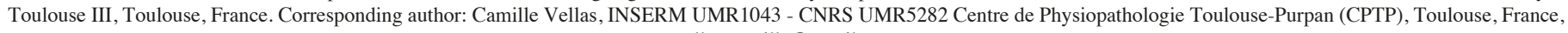
vellas.camille@gmail.com
\end{abstract}

\begin{abstract}
A new coronavirus, called SARS-CoV-2, was identified in Wuhan, China, in December 2019. The SARS-CoV-2 spread very rapidly, causing a global pandemic, Coronavirus Disease 2019 (COVID-19). Older adults have higher peak of viral load and, especially those with comorbidities, had higher COVID-19-related fatality rates than younger adults. In this Perspective paper, we summarize current knowledge about SARSCoV-2 and aging, in order to understand why older people are more affected by COVID-19. We discuss about the possibility that the so-called "immunosenescence" and "inflammaging" processes, already present in a fraction of frail older adults, could allow the immune escape of SARS-CoV-2 leading to COVID-19 serious complications. Finally, we propose to use geroscience approaches to the field of COVID-19.
\end{abstract}

Key words: COVID-19, coronavirus, SARS-CoV-2, geroscience, prevention, frailty, aging.

\section{Introduction}

Until 2002, coronaviruses (HCoV-NL63, HCoV-229E, $\mathrm{HCoV}-\mathrm{OC} 43$ and $\mathrm{HKU}$ ) were first known to cause common cold in humans. However, in 2002 the SARS-CoV emerged, and then in 2013 the MERS-CoV. The SARS-CoV and MERS$\mathrm{CoV}$ caused severe respiratory syndrome and were highly pathogenic for humans, because of their ability to adapt to their host, notably to increase affinity for their receptor, leading to high infectivity in humans $(1,2)$.

In December 2019, a new coronavirus, first called 2019nCov and then SARS-CoV-2 for severe acute respiratory syndrome coronavirus 2, was identified in Wuhan, China (3). SARS-CoV-2 spreads very efficiently, causing the current COVID-19 (Coronavirus Disease 2019) pandemic, that by midMay 2020 has already killed more than 300,000 people all over the world.

The highest morbi-mortality of COVID-19 is observed among older patients (4). Patients in intensive care unit (ICU) are older than patients not requiring ICU (5). In a study using an observational database from 169 hospitals in Asia, Europe, and North America, an age of more than 65 years-old was associated with a higher risk of in-hospital death: $10.0 \%$ mortality rates for people $\geq 65$ years-old vs. $4.9 \%$ for those < 65 years-old (6). In France, $3.6 \%$ of infected individuals needed to be hospitalized, with an average death rate of $0.7 \%$ ranging from $0.001 \%$ in individuals $<20$ years-old, to $10.1 \%$ in those $>$ 80 years-old (7).

Not all older adults appear to be equally vulnerable to SARS-CoV-2 infection (8). Frailty is a clinical syndrome in older adults characterized by an increased vulnerability for adverse health outcomes and aging-associated functional declines (9). Frail older adults, especially those with comorbidities (eg, hypertension, obesity, diabetes) are at higher risk of death if they get infected than younger adults
(10). Prevention interventions need to be developed to reduce the impact of COVID-19 in older people. Geroscience is an interdisciplinary field that seeks to understand the links of biological mechanisms of aging with biological mechanisms of disease and body functions (eg, mobility, cognition) to ultimately find potential interventions and promote health in older adults (11).

In this perspective paper, we will describe SARS-CoV-2 properties; then we will focus in the relationship between SARS-CoV-2 and aging, discussing the potential roles of comorbidities, inflammaging, immunosenescence, and immune escape. Finally, we will introduce Geroscience as a global approach to treat and prevent the onset and decrease the severity of diseases during aging, notably COVID- 19.

\section{SARS-CoV-2 properties}

Coronaviruses are members of the Coronaviridae family. They are divided into Alphacoronavirus and Betacoronavirus that can only infect mammals, and Gammacoronavirus and Deltacoronavirus which mostly infect birds (1). SARS-CoV-2 is a Betacoronavirus (subgroup B Sarbecovirus), enveloped, with a positive single-stranded large RNA that can infect animals and humans. As MERS-CoV and SARS-CoV, it may cause severe diseases and high fatality rate. The envelope spike protein of the SARS-CoV-2 recognizes the human angiotensin-converting enzyme II (ACE2) as an entry receptor, and preferentially infects lung epithelial cells $(12,13)$. The receptor binding domain of the spike protein latches onto the ACE2 receptor, and then the host TMPRSS2 protease cleaves the spike protein to expose fusion peptides able to fuse the viral and cell membranes (14).

The cellular tropism of a virus is determined by the susceptibility of host cells to be infected. This is determined, in part, by the presence of the receptor needed for entry: the 
ACE2 receptor in the case of SARS-CoV-2. ACE2 is expressed in several human tissues, including lungs, small intestine, kidneys, heart, thyroid, adipose tissue, the infection of which by the SARS-CoV-2 can result in diverse symptoms (15, 16). Common COVID-19 symptoms are fever, cough, and fatigue. Other symptoms that have also been observed include headache, diarrhea, and anosmia $(17,18)$, demonstrating that SARS-CoV-2 can infect cells in other human organs (19). In some cases, however, the infection can be asymptomatic or paucisymptomatic (causing little or no clinical manifestations) (20).

Once the SARS-CoV-2 enters a human cell, the virion releases its RNA in the cytoplasm. Translation and replication occur and new virions are then released from the cell through exocytosis (21). In COVID-19 pathology, it has been reported that the immune response can be in some cases explosive and deleterious (22). Cytokine storm, or Cytokine Release Syndrome (CRS) in peripheral blood is observed in some subjects during the second week of the COVID-19 infection. Approximately 8 days after symptom onset, when it happens in patients, the acute cytokine storm is associated with unfavorable outcomes requiring sometime ICU care and mechanical ventilation. Inflammatory factors elevated during this storm include IL-6 (interleukin 6), IFN $\gamma$ (interferon $\gamma$ ), TNF $\alpha$ (Tumor necrosis factor $\alpha$ ), IL- $1 \beta$, IL- 8, MCP-1 (CCL2 chemokine ligand 2), IP-10 (CXCL10) in peripheral blood as well as antiinflammatory factors such as IL-1RA and IL-10 (17, 22-27). Elevated IL-6 serum correlates with acute respiratory distress syndrome (ARDS) and multiple-organ failure $(23,24)$. Severe cases of COVID-19 were older, had higher levels of proinflammatory cytokines IL-6, IFN- $\gamma$ and $\mathrm{TNF} \alpha$, and lower $\mathrm{T}$ cell counts (CD8+ and CD4+ T lymphocytes) in the peripheral blood than mild cases $(26,28,29)$.

Half of the patients hospitalized for COVID-19 had a comorbidity: hypertension, 30\%; diabetes, 19\%; and coronary heart disease, $8 \%(30)$. The case-fatality rate was elevated among patients with preexisting comorbidities: cardiovascular diseases, $10.5 \%$; diabetes, $7.3 \%$; chronic respiratory disease, $6.3 \%$; hypertension, $6.0 \%$. and cancer, $5.6 \%$ (4). Patients infected by SARS-CoV-2 and with diabetes had higher levels of IL-6, IL-8, and TNF $\alpha$ in peripheral blood, and were older than patients without diabetes (31). Most of the fatal cases of COVID-19 involved older adults and patients with comorbidities. Cardiovascular diseases, hypertension, cancer, diabetes are also age-related diseases (32); and are associated with a chronic inflammation, as aging.

\section{SARS-CoV-2 and aging}

During the current SARS-CoV-2 pandemic, patients in ICU have higher levels of inflammatory factors, and are significantly older and with comorbidities than patients who are not in $\operatorname{ICU}(5,30)$. Older age is also associated with a higher peak viral load in the naso-pharynx, suggesting that the virus could replicate at higher rates in older adults, or more probably that their immune system is not efficient enough to limit the infection (33-35). Differences of ACE2 expression level between young and old adults could contribute to the higher viral loads in older adults, even though this is not established yet in the literature; whereas one study suggests that ACE2 expression in the lung increases with age (36), another investigation (16) indicates that ACE2 expression levels showed no significant difference between younger and older adults. This discrepancy deserves further studies. When ACE2 expression in the lungs was associated with immune signatures (genes expression of $\mathrm{CD} 8+\mathrm{T}$ cells, type I IFN response, $\mathrm{B}$ cells and NK cells), a positive correlation was observed in the older group and a negative correlation in the younger one (16). The ability of the host immune response to combat SARS-CoV-2 infection may partially explain the difference in severity between young and old adults. The induction of proinflammatory cytokines during sepsis (as it may occur in COVID-19 pathology) is not always adequately controlled by anti-inflammatory mechanisms, notably in older patients (37). People respond differently to the infection and older patients or those with comorbidities could more frequently have an inappropriate immune response. We can speculate that it is not the SARS-CoV-2 itself, but the inappropriate immune response and the inflammatory process that are responsible for the higher mortality of COVID-19 among older patients $(29,38)$.

In COVID-19 clinical studies, chronological age has been used, whereas all individuals do not age in the same way and the underlying mechanisms of aging may be different. Frailty is a clinical syndrome common in older adults. It has been defined by Fried et al. (9) as a clinical syndrome in which at least three of the following criteria are present: unintentional weight loss, self-reported exhaustion, weakness, slow walking speed, and low physical activity. Aging and frailty change the clinical presentation of infections, due to alterations in temperature regulation, cognitive decline or malnutrition. Fever may not be detected in older adults and we need to be aware about all the clinical manifestations of COVID-19 for an early identification of frail individuals infected by the SARS-CoV-2 $(29,39)$. There is evidence that inflammaging and immunosenescence have key roles in the pathophysiology of frailty (40).

Inflammaging is a low-grade persistent increase in inflammatory mediators (41). During aging, chronic antigenic stress (eg, chronic infection, microbiota translocation) leads to chronic low-grade inflammation, as a mechanism of defense; but the regulation by anti-inflammatory molecules is lacking in some older adults and this chronic inflammation become deleterious (42). Senescent cells have a Senescence-AssociatedSecretory-Phenotype (SASP) and secrete high levels of inflammatory mediators such as IL-6, IL-1 $\beta$, TNF $\alpha$ and other molecules (IL-18, IL-8, CCL2, CCL11), growth factors and proteases $(41,43-47)$. The SASP is a characteristic of senescent cells with arrested cell growth and resistance to apoptosis. It can also be expressed by CD4+ T cells (SA-T) and senescent CD8+ 
Table 1

Characteristics of immunosenescence: decline in immune functions; and immune consequences of SARS-CoV-2 infection in older people

\begin{tabular}{|c|c|c|c|c|}
\hline & Immune characteristics & Mechanisms & Consequences & References \\
\hline \multirow{4}{*}{ Immunosenescence } & $\begin{array}{l}\text { Reduction of } \mathrm{B} \text { and } \mathrm{T} \text { cells } \\
\text { production }\end{array}$ & $\begin{array}{l}\text { Stem cell aging with } \\
\text { reduced capacity to produce } \\
\text { lymphocytes, reduction in the } \\
\text { number of B cell and T cell } \\
\text { progenitors in bone marrow and } \\
\text { thymus }\end{array}$ & $\begin{array}{l}\text { Vulnerability to infections } \\
\text { and cancer; Impaired res- } \\
\text { ponse to vaccination }\end{array}$ & Goronzy JJ et al., 2019 \\
\hline & Impaired B cells function & $\begin{array}{l}\text { B cell number reduced in } \\
\text { peripheral blood. Decreased } \\
\text { numbers of IgM+ memory and } \\
\text { switched memory B cells }\end{array}$ & & Frasca D et al., 2009 \\
\hline & $\begin{array}{l}\text { Compromise communi- } \\
\text { cation between innate and } \\
\text { adaptive immunity }\end{array}$ & $\begin{array}{l}\text { Activated naive } \mathrm{CD} 4 \mathrm{~T} \text { cells } \\
\text { have reduced responses to type } \\
\text { I IFN }\end{array}$ & $\begin{array}{l}\text { Lack in the regulation of } \\
\text { T cell differentiation and } \\
\text { survival. Vulnerability to } \\
\text { infections }\end{array}$ & Shaw AC et al., 2010 \\
\hline & $\begin{array}{l}\text { Low type I and III IFN } \\
\text { response }\end{array}$ & $\begin{array}{l}\text { Reduced number of plasma- } \\
\text { cytoid dendritic cells IFN } \\
\text { producers; inadequate CD4 T } \\
\text { cells response to type I IFN } \\
\text { stimulation, that impairs IL-2 } \\
\text { production and cell survival }\end{array}$ & & $\begin{array}{l}\text { Agrawal A et al., } 2013 \\
\text { Li et al., } 2015\end{array}$ \\
\hline$S A R S-C o V-2$ & Lymphopenia & $\begin{array}{l}\text { SARS-CoV-2 could infect T } \\
\text { cells. Apoptosis of lymphocytes } \\
\text { induces lymphocytopenia like in } \\
\text { MERS-CoV infection? }\end{array}$ & & $\begin{array}{l}\text { Yang X et al., } 2020 \\
\text { Wang X et al., } 2020\end{array}$ \\
\hline
\end{tabular}

$\mathrm{T}$ cells, associating inflammaging and immunosenescence $(48$, 49).

It is well established that the immune response decreases with aging: reduced production of $\mathrm{B}$ and $\mathrm{T}$ cells in bone marrow and thymus, diminished function of mature lymphocytes in secondary lymphoid tissues, increase in the number of memory $\mathrm{T}$ cells, chronic stimulation (with persistent viral infection by
Cytomegalovirus and others), impaired function of B cells, and compromised communication between innate and adaptive immunity (Table 1) (50-57). This series of age-related changes affecting the immune system is called "immunosenescence" (45). It affects principally the adaptive immune response. The consequence of immunosenescence is characterized by an increase in vulnerability, and poor resolution of homeostasis 
Table 2

Ongoing clinical trials with anti-aging drugs and COVID-19. (from ClinicalTrials.gov)

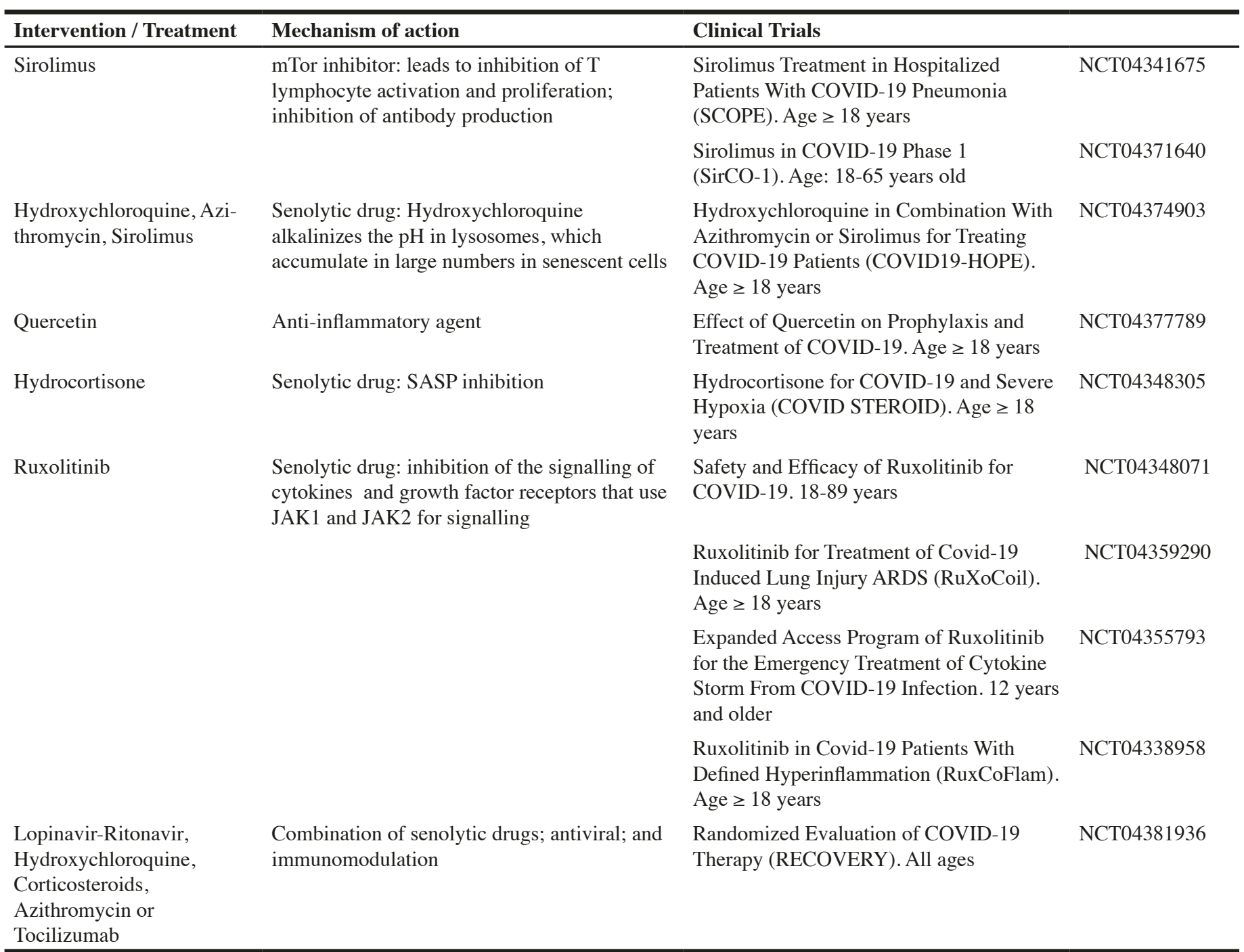

following a stress, that may lead to low resilience and frailty. Infections in frail adults often lead to large deterioration and functional dependency which does not return to baseline homeostasis (40). The decline immune functions of frail persons may lead to higher SARS-CoV-2 replication and more severe COVID-19.

The immunosenescence is also characterized by a delayed type I interferons (IFN) response (56). Type I interferons (IFNs) are polypeptides secreted by infected cells. They induce an antimicrobial state in infected and neighboring cells to limit the spread of the virus. IFNs can also modulate innate immune responses in order to promote antigen presentation, natural killer cell functions and to restrain the production of proinflammatory mediators. Finally, IFNs activate the adaptive immune system (high-affinity antigen-specific $\mathrm{T}$ and $\mathrm{B}$ cell responses) (58). The lack of type I IFN response in frail older adults leads to a low adaptive immune response (56). SARSCoV-2 is a virus sensitive to type I IFN; however, it is also able to limit type I IFN induction $(25,29)$. With this function, the virus could escape from the human immune response. Thus, the IFN-I response is limited by the immunosenescence in the host, as well as by the virus itself; explaining why frail patients could be more affected by the COVID-19 (Table 1). Moreover, lymphopenia during COVID-19 infection correlates with clinical severity, and occurs in $80 \%$ of critically ill patients (59). A recent study from Wang et al., showed that similar to MERS-CoV, the SARS-CoV-2 can infect $\mathrm{T}$ cells but failed to replicate in $\mathrm{T}$ lymphocytes (60). If the SARS-CoV-2 could induces the apoptosis of T cells as the MERS-CoV-2, this could have a significant negative impact on frail older people with already reduced $\mathrm{T}$ cell production (61).

Taken together, inflammaging and immunosenescence, 


\section{THE JOURNAL OF NUTRITION, HEALTH \& AGING}

Figure 1

Circle of aging and SARS-CoV-2 infection

With age, the immune system declines leading to frailty, comorbidities and high susceptibility to infections. This immune decline can be a predisposing condition sustaining COVID-19 serious complications and explaining high mortality rates in older people with COVID-19. We hypothesize that COVID-19 can be a future cause of accelerated aging and frailty

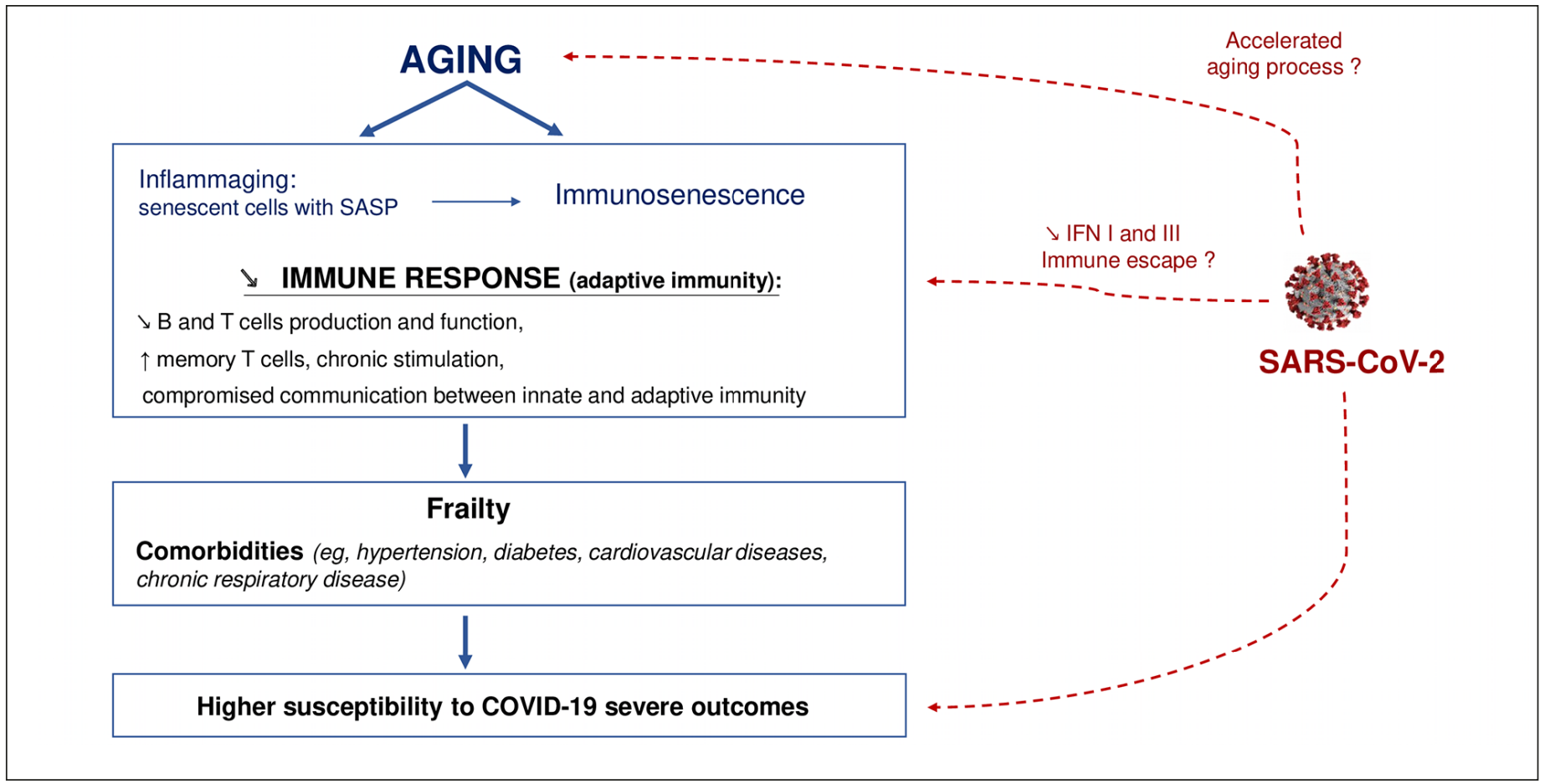

observed in frail adults, can results in a decrease of the immune system ability to fight new challenges (as SARS-CoV-2 infection). On the other hand, the SARS-CoV-2 may accentuate this immune decline, by its capacity of limiting type I IFN response and maybe infecting $\mathrm{T}$ cells. All of this could result in an unstopped SARS-CoV-2 infection and leads to COVID-19 complications in frail older adults.

\section{Geroscience: a global approach to treat and prevent COVID-19 or future pandemic}

As of May 2020, there are no specific therapies approved for COVID-19 treatment. One strategy is to use drugs that are already approved and known to work at different stages of viral infection and against the immune response. The use of these drugs fast-tracks a treatment plan in a global pandemic situation. Two therapeutic strategies can be distinguished: agents that can target the virus, and agents that protect the host. In the former category, trials are focused on drugs that limit entry or replication (eg, Remdesivir, Lopinavir/Ritonavir, Hydroxychloroquine, IFN $\alpha, \operatorname{IFN} \beta$ ) (62). For the latter, the focus is on drugs that can limit the human inflammatory response (eg, corticosteroids, Tocilizumab which is an antiIL-6R) or boost the innate antiviral immune response (BCG vaccine, type I IFN) (63).

The approaches boosting innate antiviral immune response are more interesting for older persons with a weakened immune system, but the risk is to introduce the drugs too late in the infection process. Identifying people at-risk for COVID-19 is necessary to put in place effective and personalized preventive measures. To identify at-risk people, it would be interesting to determine their "immune-age" or "biological age" (64) rather than relying only on chronological age. It will ensure a personalized therapeutic care, with benefits against SARSCoV-2 infection.

In a more global perspective, geroscience should be associated to COVID-19 prevention and treatment $(64,65)$. Geroscience seeks to understand all biological mechanisms (genetic, molecular, and cellular) that make aging a major risk factor of chronic diseases of older adults. The aim is to target the aging process as the single most important risk factor instead of treating just the infection. Treatments that target the molecular pathways of aging could decrease the development and severity of age-related disease, and more globally comorbidities. Among these agents, senolytics can selectively induce death of senescent cells, limiting the accumulation of SASP. Senolytic drugs (eg, quercetin, dasatinib, ruxolitinib) might have a beneficial effect for the prevention or the treatment of SARS-CoV-2 infection by attenuating the cytokine storm and reducing immunosenescence $(67,68)$. mTor inhibitors (eg, rapamycin, RTB101, everolimus) are approved for use in humans and are known to delay age-related diseases 


\section{COVID-19, VIROLOGY AND GEROSCIENCE: A PERSPECTIVE}

in multiple animal models (69). A limited number of clinical trials with these drugs are currently being conducted to evaluate their effectiveness against COVID-19 (Table 2) (70).

Comorbidities such as hypertension, coronary heart disease or type 2 diabetes are additional risk factors for COVID-19 pathology and complications (71). These comorbidities are also considered to be aging-associated diseases. Current geroscience research aims at determining biological age and could help in the future to determine which older adults are most at risk for complication when infected by SARS-CoV-2. This approach is not specific to COVID-19, and it could be a benefic prevention to protect older adults against future epidemics.

The potential long-term effects of COVID-19 are still unclear. This infection could be a future cause of accelerated aging and frailty. Using geroscience approaches will help to identify this risk.

\section{Conclusions and Perspective}

In summary, SARS-CoV-2 is an emerging highly transmissible coronavirus that causes high mortality in the aging population $(6,7,72,73)$. The aging population is heterogeneous but most have comorbidities. These comorbidities (eg, hypertension, cardiovascular diseases, obesity, diabetes) are correlated with COVID-19 serious complications (4).

The SARS-CoV-2 virus infects human cells by a recognition between the viral spike protein and the human ACE2 receptor (13). The increase of the ACE2 receptor expression with age is still debated; but the peak viral load seems correlated with age (35).

During aging, immunosenescence and inflammaging are suggested to stand at the origin of frailty and diseases in older individuals (43). The inflammaging results of a chronic inflammation, with low-grade production of inflammatory mediators; and the immunosenescence is characterized by a loss in adaptive immune functions that reinforces the need to find treatments that stimulate the innate immune response to protect the organism from infection (42). Immunosenescence and inflammaging occurring in some older adults, could be predisposing conditions that sustain the mechanisms by which the SARS-CoV-2 escape the immune surveillance and leads to serious COVID-19 (Figure 1).

The effect of aging on the immune system is not uniform among individuals. Now that countries are striking down stay-at-home orders, an ultimate goal would be to identify at-risk older people through their aging profile and develop a personalized approach to limit COVID-19 complications. We propose to use geroscience approaches to identify at-risk people (74), develop drugs targeting molecular pathway of aging, and prevent COVID-19 serious complications $(66,75)$.$$
\text { A }
$$
paper.
Author Contributions: C Vellas wrote the manuscript. P Delobel, J Izopet and P de Souto Barreto provided substantial edits and suggestions of each drafts. All authors edited and approved the final manuscript.

Competing Interests: The authors declare no conflict of interest.

\section{References}

1. Cui J, Li F, Shi Z-L. Origin and evolution of pathogenic coronaviruses. Nat Rev Microbiol 2019;17:181-192.

2. Li W, Zhang C, Sui J, Kuhn JH, Moore MJ, Luo S, Wong S-K, Huang I-C, Xu K, Vasilieva N, Murakami A, He Y, Marasco WA, Guan Y, Choe H, Farzan M. Receptor and viral determinants of SARS-coronavirus adaptation to human ACE2. EMBO J $2005 ; 24: 1634-1643$.

3. Wu F, Zhao S, Yu B, et al. A new coronavirus associated with human respiratory disease in China. Nature 2020;579:265-269.

4. Wu Z, McGoogan JM. Characteristics of and Important Lessons From the Coronavirus Disease 2019 (COVID-19) Outbreak in China: Summary of a Report of 72314 Cases From the Chinese Center for Disease Control and Prevention. JAMA. 2020; doi:10.1001/jama.2020.2648.

5. Wang D, Hu B, Hu C, Zhu F, Liu X, Zhang J, Wang B, Xiang H, Cheng Z, Xiong Y, Zhao Y, Li Y, Wang X, Peng Z. Clinical Characteristics of 138 Hospitalized Patients With 2019 Novel Coronavirus-Infected Pneumonia in Wuhan, China. JAMA. 2020; doi:10.1001/jama.2020.1585.

6. Mehra MR, Desai SS, Kuy S, Henry TD, Patel AN. Cardiovascular Disease, Drug Therapy, and Mortality in Covid-19. N Engl J Med. 2020; doi:10.1056/ NEJMoa2007621.

7. Salje H, Kiem CT, Lefrancq N, Courtejoie N, Bosetti P, Paireau J, Andronico A, Hozé N, Richet J, Dubost C-L, Strat YL, Lessler J, Levy-Bruhl D, Fontanet A, Opatowski L, Boelle P-Y, Cauchemez S. Estimating the burden of SARS-CoV-2 in France. Science. 2020; doi:10.1126/science.abc3517.

8. Nickel CH, Rueegg M, Pargger H, Bingisser R. Age, comorbidity, frailty status: effects on disposition and resource allocation during the COVID-19 pandemic. Swiss Med Wkly 2020;150:w20269.

9. Fried LP, Tangen CM, Walston J, Newman AB, Hirsch C, Gottdiener J, Seeman T, Tracy R, Kop WJ, Burke G, McBurnie MA, Cardiovascular Health Study Collaborative Research Group. Frailty in older adults: evidence for a phenotype. J Gerontol A Biol Sci Med Sci 2001;56:M146-156.

10. Richardson S, Hirsch JS, Narasimhan M, et al. Presenting Characteristics, Comorbidities, and Outcomes Among 5700 Patients Hospitalized With COVID-19 in the New York City Area. JAMA. 2020; doi:10.1001/jama.2020.6775.

11. Sierra F. The Emergence of Geroscience as an Interdisciplinary Approach to the Enhancement of Health Span and Life Span. Cold Spring Harb Perspect Med 2016;6:a025163.

12. Velavan TP, Meyer CG. The COVID-19 epidemic. Trop Med Int Health TM IH 2020;25:278-280.

13. Zhang H, Penninger JM, Li Y, Zhong N, Slutsky AS. Angiotensin-converting enzyme 2 (ACE2) as a SARS-CoV-2 receptor: molecular mechanisms and potential therapeutic target. Intensive Care Med 2020;46:586-590.

14. Hoffmann M, Kleine-Weber H, Schroeder S, Krüger N, Herrler T, Erichsen S, Schiergens TS, Herrler G, Wu N-H, Nitsche A, Müller MA, Drosten C, Pöhlmann S. SARS-CoV-2 Cell Entry Depends on ACE2 and TMPRSS2 and Is Blocked by a Clinically Proven Protease Inhibitor. Cell. 2020; doi:10.1016/j.cell.2020.02.052.

15. Hamming I, Timens W, Bulthuis MLC, Lely AT, Navis GJ, van Goor H. Tissue distribution of ACE2 protein, the functional receptor for SARS coronavirus. A first step in understanding SARS pathogenesis. J Pathol 2004;203:631-637.

16. Li M-Y, Li L, Zhang Y, Wang X-S. Expression of the SARS-CoV-2 cell receptor gene ACE2 in a wide variety of human tissues. Infect Dis Poverty 2020;9:45.

17. Rothan HA, Byrareddy SN. The epidemiology and pathogenesis of coronavirus disease (COVID-19) outbreak. J Autoimmun:2020;102433.

18. Jiang F, Deng L, Zhang L, Cai Y, Cheung CW, Xia Z. Review of the Clinical Characteristics of Coronavirus Disease 2019 (COVID-19). J Gen Intern Med 2020;35:1545-1549.

19. Lamers MM, Beumer J, van der Vaart J, et al. SARS-CoV-2 productively infects human gut enterocytes. Science. 2020; doi:10.1126/science.abc1669.

20. Treibel TA, Manisty C, Burton M, McKnight Á, Lambourne J, Augusto JB, CoutoParada X, Cutino-Moguel T, Noursadeghi M, Moon JC. COVID-19: PCR screening of asymptomatic health-care workers at London hospital. Lancet Lond Engl. 2020; doi:10.1016/S0140-6736(20)31100-4.

21. Chen Y, Liu Q, Guo D. Emerging coronaviruses: Genome structure, replication, and pathogenesis. J Med Virol 2020;92:418-423.

22. Pedersen SF, Ho Y-C. SARS-CoV-2: a storm is raging. J Clin Invest 2020;130:22022205 . 


\section{THE JOURNAL OF NUTRITION, HEALTH \& AGING}

23. Moore JB, June CH. Cytokine release syndrome in severe COVID-19. Science 2020;368:473-474.

24. Ye Q, Wang B, Mao J. The pathogenesis and treatment of the 'Cytokine Storm' in COVID-19. J Infect. 2020; doi:10.1016/j.jinf.2020.03.037.

25. Blanco-Melo D, Nilsson-Payant BE, Liu W-C, Uhl S, Hoagland D, Møller R, Jordan TX, Oishi K, Panis M, Sachs D, Wang TT, Schwartz RE, Lim JK, Albrecht RA, tenOever BR. Imbalanced Host Response to SARS-CoV-2 Drives Development of COVID-19. Cell. 2020; doi:10.1016/j.cell.2020.04.026.

26. Liu J, Li S, Liu J, et al. Longitudinal characteristics of lymphocyte responses and cytokine profiles in the peripheral blood of SARS-CoV-2 infected patients. EBioMedicine. 2020; doi:10.1016/j.ebiom.2020.102763.

27. Lin $\mathrm{L}, \mathrm{Lu} \mathrm{L}, \mathrm{Cao} \mathrm{W}, \mathrm{Li} \mathrm{T}$. Hypothesis for potential pathogenesis of SARS-CoV-2 infection-a review of immune changes in patients with viral pneumonia. Emerg Microbes Infect 2020;9:727-732.

28. Velavan TP, Meyer CG. Mild versus severe COVID-19: Laboratory markers. Int J Infect Dis IJID Off Publ Int Soc Infect Dis 2020;95:304-307.

29. Chen G, Wu D, Guo W, et al. Clinical and immunological features of severe and moderate coronavirus disease 2019. J Clin Invest 2020;130:2620-2629.

30. Zhou F, Yu T, Du R, et al. Clinical course and risk factors for mortality of adul inpatients with COVID-19 in Wuhan, China: a retrospective cohort study. Lancet Lond Engl 2020;395:1054-1062.

31. Yan Y, Yang Y, Wang F, Ren H, Zhang S, Shi X, Yu X, Dong K. Clinical characteristics and outcomes of patients with severe covid-19 with diabetes. BMJ Open Diabetes Res Care 2020;8. doi:10.1136/bmjdrc-2020-001343.

32. Jaul E, Barron J. Age-Related Diseases and Clinical and Public Health Implications for the 85 Years Old and Over Population. Front Public Health 2017;5. doi:10.3389/ fpubh.2017.00335.

33. Chen Y, Li L. SARS-CoV-2: virus dynamics and host response. Lancet Infect Dis 2020;20:515-516.

34. To KK-W, Tsang OT-Y, Leung W-S, et al. Temporal profiles of viral load in posterior oropharyngeal saliva samples and serum antibody responses during infection by SARS-CoV-2: an observational cohort study. Lancet Infect Dis 2020;20:565-574.

35. Pan Y, Zhang D, Yang P, Poon LLM, Wang Q. Viral load of SARS-CoV-2 in clinical samples. Lancet Infect Dis 2020;20:411-412.

36. Chen Y, Shan K, Qian W. Asians Do Not Exhibit Elevated Expression or Unique Genetic Polymorphisms for ACE2, the Cell-Entry Receptor of SARS-CoV-2. 2020 doi:10.20944/preprints202002.0258.v2.

37. Opal SM, Girard TD, Ely EW. The immunopathogenesis of sepsis in elderly patients Clin Infect Dis Off Publ Infect Dis Soc Am 200541 Suppl 2005;7:S504-512.

38. Zhang X, Tan Y, Ling Y, et al. Viral and host factors related to the clinical outcome of COVID-19. Nature:2020;1-7.

39. El Chakhtoura NG, Bonomo RA, Jump RLP. Influence of Aging and Environment on Presentation of Infection in Older Adults. Infect Dis Clin North Am 2017:31:593-608.

40. Clegg A, Young J, Iliffe S, Rikkert MO, Rockwood K. Frailty in elderly people. Lancet Lond Engl 2013;381:752-762.

41. Franceschi C, Campisi J. Chronic inflammation (inflammaging) and its potential contribution to age-associated diseases. J Gerontol A Biol Sci Med Sci 2014;69 Suppl 1:S4-9.

42. Fulop T, Larbi A, Dupuis G, Le Page A, Frost EH, Cohen AA, Witkowski JM, Franceschi C. Immunosenescence and Inflamm-Aging As Two Sides of the Same Coin: Friends or Foes? Front Immunol 2017;8:1960.

43. Franceschi C, Garagnani P, Parini P, Giuliani C, Santoro A. Inflammaging: a new immune-metabolic viewpoint for age-related diseases. Nat Rev Endocrinol 2018;14:576-590.

44. de Keizer PLJ. The Fountain of Youth by Targeting Senescent Cells? Trends Mol Med 2017;23:6-17.

45. Nikolich-Žugich J. The twilight of immunity: emerging concepts in aging of the immune system. Nat Immunol 2018;19:10-19.

46. Coppé J-P, Desprez P-Y, Krtolica A, Campisi J. The Senescence-Associated Secretory Phenotype: The Dark Side of Tumor Suppression. Annu Rev Pathol 2010;5:99-118.

47. Schmeer C, Kretz A, Wengerodt D, Stojiljkovic M, Witte OW. Dissecting Aging and Senescence-Current Concepts and Open Lessons. Cells 2019;8. doi:10.3390/ cells8111446.

48. Fukushima Y, Minato N, Hattori M. The impact of senescence-associated T cells on immunosenescence and age-related disorders. Inflamm Regen 2018;38. doi:10.1186/ s41232-018-0082-9.

49. Callender LA, Carroll EC, Beal RWJ, Chambers ES, Nourshargh S, Akbar AN Henson SM. Human CD8+ EMRA T cells display a senescence-associated secretory phenotype regulated by p38 MAPK. Aging Cell 2018;17. doi:10.1111/acel.12675.

50. Montecino-Rodriguez E, Berent-Maoz B, Dorshkind K. Causes, consequences, and reversal of immune system aging. J Clin Invest 2013;123:958-965.
51. Klenerman P, Oxenius A. T cell responses to cytomegalovirus. Nat Rev Immunol 2016;16:367-377.

52. Goronzy JJ, Weyand CM. Mechanisms underlying T cell ageing. Nat Rev Immunol 2019; 19:573-583.

53. Frasca D, Blomberg BB. Effects of aging on B cell function. Curr Opin Immunol 2009;21:425-430.

54. Shaw AC, Goldstein DR, Montgomery RR. Age-dependent dysregulation of innate immunity. Nat Rev Immunol 2013;13:875-887.

55. Chiu PWY, Ng SC, Inoue H, Reddy DN, Ling Hu E, Cho JY, Ho LK, Hewett DG, Chiu H-M, Rerknimitr R, Wang H-P, Ho SH, Seo DW, Goh K-L, Tajiri H, Kitano S, Chan FKL. Practice of endoscopy during COVID-19 pandemic: position statements of the Asian Pacific Society for Digestive Endoscopy (APSDE-COVID statements). Gut 2020; doi:10.1136/gutjnl-2020-321185

56. Agrawal A. Mechanisms and implications of age-associated impaired innate interferon secretion by dendritic cells: a mini-review. Gerontology 2013;59:421-426.

57. Li G, Ju J, Weyand CM, Goronzy JJ. Age-associated Failure to Adjust Type Interferon Receptor Signaling Thresholds after T-cell Activation. J Immunol Baltim Md 2015;1950 195:865-874.

58. Ivashkiv LB, Donlin LT. Regulation of type I interferon responses. Nat Rev Immunol 2014;14:36-49.

59. Yang X, Yu Y, Xu J, Shu H, Xia J, Liu H, Wu Y, Zhang L, Yu Z, Fang M, Yu T, Wang Y, Pan S, Zou X, Yuan S, Shang Y. Clinical course and outcomes of critically ill patients with SARS-CoV-2 pneumonia in Wuhan, China: a single-centered, retrospective, observational study. Lancet Respir Med 2020;8:475-481.

60. Wang X, Xu W, Hu G, Xia S, Sun Z, Liu Z, Xie Y, Zhang R, Jiang S, Lu L. SARS $\mathrm{CoV}-2$ infects $\mathrm{T}$ lymphocytes through its spike protein-mediated membrane fusion. Cell Mol Immunol:2020;1-3.

61. Ying T, Li W, Dimitrov DS. Discovery of T-Cell Infection and Apoptosis by Middle East Respiratory Syndrome Coronavirus. J Infect Dis 2016;213:877-879.

62. Ferner RE, Aronson JK. Chloroquine and hydroxychloroquine in covid-19. BMJ 2020;369:m1432.

63. Sanders JM, Monogue ML, Jodlowski TZ, Cutrell JB. Pharmacologic Treatments for Coronavirus Disease 2019 (COVID-19): A Review. JAMA. 2020; doi:10.1001/ jama.2020.6019.

64. Alpert A, Pickman Y, Leipold M, Rosenberg-Hasson Y, Ji X, Gaujoux R, Rabani H, Starosvetsky E, Kveler K, Schaffert S, Furman D, Caspi O, Rosenschein U, Khatri P, Dekker CL, Maecker HT, Davis MM, Shen-Orr SS. A clinically meaningful metric of immune age derived from high-dimensional longitudinal monitoring. Nat Med 2019;25:487-495.

65. Promislow DEL. A geroscience perspective on COVID-19 mortality. J Gerontol A Biol Sci Med Sci 2020; doi:10.1093/gerona/glaa094.

66. Beard JR. Editorial: Linking Geroscience and Integrated Care to Reinforce Prevention. J Prev Alzheimers Dis 2020;7:68-69.

67. Sargiacomo C, Sotgia F, Lisanti MP. COVID-19 and chronological aging: senolytics and other anti-aging drugs for the treatment or prevention of corona virus infection? Aging 2020;12:6511-6517.

68. Xu M, Pirtskhalava T, Farr JN, et al. Senolytics improve physical function and increase lifespan in old age. Nat Med 2018;24:1246-1256.

69. Johnson SC, Rabinovitch PS, Kaeberlein M. mTOR is a key modulator of ageing and age-related disease. Nature 2013;493:338-345.

70. Zhavoronkov A. The inherent challenges of classifying senescence. Science 2020;368:595.

71. Abbatecola AM, Antonelli-Incalzi R. Editorial: COVID-19 Spiraling of Frailty in Older Italian Patients. J Nutr Health Aging 2020;24:453-455.

72. Merchant RA, Chen MZ, Ng SE, Sandrasageran S, Wong BLL. The Role of a Geriatrician has Become Even More Important in an Academic Institution during COVID-19. J Nutr Health Aging:2020;1-2.

73. Aprahamian I, Cesari M. Geriatric Syndromes and SARS-COV-2: More than Just Being Old. J Frailty Aging:2020;1-3.

74. Sanchez-Rodriguez D, Annweiler C, Gillain S, Vellas B. Implementation of the Integrated Care of Older People (ICOPE) App in Primary Care: New Technologies in Geriatric Care During Quarantine of COVID-19 and Beyond. J Frailty Aging.2020; doi: $10.14283 /$ jfa.2020.24

75. Sierra F. Geroscience and the Coronavirus Pandemic: The Whack-a-Mole Approach is not Enough. J Am Geriatr Soc. 2020; doi:10.1111/jgs.16489 